\title{
Cardiovascular dysphagia - anatomical and clinical implications
}

\author{
S.-M. Yuan \\ $1^{\text {st }}$ Hospital of Putian, Teaching Hospital, Fujian Medical University, Putian, Fujian Province, People's Republic of China
}

[Received 28 November 2013; Accepted 5 January 2014]

\begin{abstract}
Cardiovascular dysphagia is rare. The aetiologies can be congenital, acquired or iatrogenic. The severity of dysphagia can be mild or severe, consistent or progressive, depending on the nature of the cardiovascular disorder and the impact for oesophageal compressions. The diagnostic work-up includes standard chest radiography, chest computed tomography, endoscopy, barium swallow test and manometry. Treatment can be conservative, surgical or palliative according to the nature of the disorder and the severity of the symptom. Prognoses of the patients are always good. Although cardiovascular dysphagia is continuously reported as sporadic cases, there have not been any comprehensive declarations of the conditions in the literature. Present article aims to make a comprehensive review of cardiovascular dysphagia. Folia Morphol 2014; 73, 2: 113-121)
\end{abstract}

Key words: digestive system fistula, deglutition disorders, thoracic aorta

\section{INTRODUCTION}

Dysphagia can be functional and mechanical. Functional dysphagia is caused by weak oesophageal peristalsis and motility disorders such as achalasia, myasthenia gravis and bulbar or pseudobulbar palsy, whereas mechanical dysphagia is due to mechanical obstruction of the oesophagus such as bolus obstruction, stricture and hiatal hernia, etc. [51]. There have been several cardiovascular conditions that were in association to dysphagia. Dysphagia lusoria (or Bayford-Autenrieth dysphagia) is one of the most commonly described congenital situations in charge of dysphagia, which is caused by an aberrant right subclavian artery (ARSA). Dysphagia aortica is another concept interpreting dysphagia by external compression of the oesophagus due to aortic aneurysm or astherosclerotically enlarged aorta [53]. The concept of 'cardiovascular dysphagia' was firstly proposed by Cappell [16], followed by Gotsman et al. [44] in 1999.
Since then, cardiovascular dysphagia was increasingly described with different aetiologies, with majority of them being the congenital aortic disorders and aorto-oesophageal fistula. Apart from sporadic reports with anecdotal results, however, no comprehensive declarations of the conditions have been found so far. Present article aims to make a comprehensive review of cardiovascular dysphagia.

\section{CONGENITAL CARDIOVASCULAR DYSPHAGIA}

\section{Double aortic arch}

In double aortic arch (DAA), the ascending aorta divides into the left anterior and the right posterior arches, which encircle the trachea and oesophagus, and joins posteriorly to be continued with the descending thoracic aorta (Fig. 1A). The retro-oesophageal right arch passes the midline posteriorly and compresses

Address for correspondence: Dr S.-M. Yuan, $1^{\text {st }}$ Hospital of Putian, Teaching Hospital, Fujian Medical University, Putian, Fujian Province, People's Republic of China, tel: 86594 6923117, e-mail: shi_min_yuan@yahoo.com, shiminyuan@126.com 

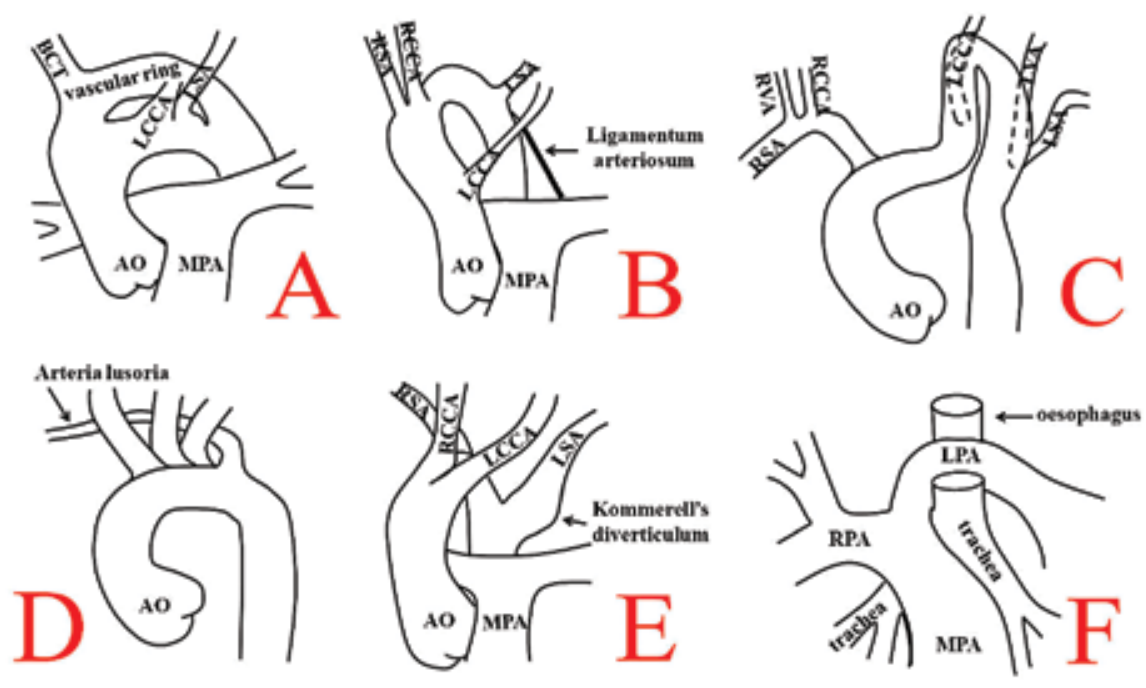

Figure 1. Schematic diagrams of dysphagia aortica of congenital aetiologies; A. Double aortic arch; B. Right aortic arch; C. Cervical aortic arch; D. Arteria lusoria; E. Kommerell's diverticulum; F. Pulmonary artery sling; AO — aorta; BCT — brachiocephalic trunk; LCCA — left common carotid artery; LPA — left pulmonary artery; LSA — left subclavian artery; LVA — left vertebral artery; MPA — main pulmonary artery; RCCA — right common carotid artery; RPA — right pulmonary artery; RSA — right subclavian artery; RVA — right vertebral artery.

the oesophagus, resulting in dysphagia. The left arch between the left subclavian and the left-sided descending thoracic aorta is atretic. The atretic arch constricting the mid-oesophagus is divided between vascular clamps, between the left subclavian and the descending aorta [93]. DAA can be divided into 2 types: type a DAA with both arches patent; and type $B$ DAA with left arch atresia distal to the origin of the left subclavian artery and left ligamentum [30]. Type B DAA can be further classified into 4 subtypes according to the site of atresia: subtype 1 , between the ligamentum and the descending thoracic aorta; subtype 2 , between the left subclavian and the ligamentum arteriosum; subtype 3 , between the left carotid and the left subclavian arteries; and subtype 4: proximal to the left common carotid artery [52]. DAA often causes tracheal and oesophageal compressions in children, but adults with DAA are usually asymptomatic or with mild symptoms [58]. An association of oesophageal carcinoma with DAA was once reported, and the patients' symptoms including dysphagia and nausea were considered to be caused not by the oesophageal carcinoma itself, but by the DAA, evidenced by oesophagographic demonstrations of smooth upper thoracic oesophagus. Merely subtotal oesophagectomy without division and ligation of the lesser aortic arch relieved the patient's symptoms [63]. Surgical division is indicated in all symptomatic patients and provides excellent operative results. Division of the left aortic arch just distal to the origin of the left subclavian artery and division of the ligamentum arteriosum via left posterolateral thoracotomy may free the oesophagus and alleviate the patient's symptoms [41]. Division of the minor arch and ligamentum arteriosum is indicated for symptomatic adult patients. Thoracotomy should be on the ipsilateral side of aortic compression and the ligamentum arteriosum, which warrants ligation and division for relieving oesophageal compression. In the patients with a complete vascular ring formed by a fibrous strand, left-sided innominate artery and Kommerell's diverticulum, ligation and resection of the Kommerell's diverticulum, atretic left arch and ductus arteriosus are warranted [89]. Aortopexy, i.e., the aorta is pexied to the spine after external oesophageal compression is completely relieved, is an option of treatment. Division of left arch with ligament division is necessary in the patients with left arterial ligament with dysphagia [13].

\section{Right aortic arch}

Right aortic arch (RAA) is when the aortic arch crosses over the right main stem bronchus instead of the usual left main stem bronchus (Fig. 1B). It can be divided into 2 main types: type 1 with mirror-image branching, where there is no vascular ring present, and type 2 , with an aberrant left subclavian 
artery (ALSA), forming a vascular ring by ventral position of the ligamentum arteriosum. The incidence of RAA is about $0.1-0.2 \%$ in adults [86], and $50 \%$ of RAAs are associated with the ALSA $[26,61]$. The patients' age at the onset was reported to be 40.5 (range 17-55) years, with significant male predominance. The retro-oesophageal RAA often causes oesophageal compression [59]. The most common symptoms of the patients with RAA are exertional dyspnoea and dysphagia [77]. Paediatric patients are often presented with severe respiratory distress and dysphagia. In adults, dysphagia is the most reported symptom [68]. Aneurysmal dilation of the RAA may cause dysphagia as well [80]. RAA with ALSA is an uncommon entity, and the patients are often asymptomatic. However, adults may manifest dysphagia [88]. Aberrant subclavian artery originating from the right descending aortic arch often courses behind the oesophagus and trachea, and converges with the left subclavian artery, constituting a vascular ring. Resection of the retro-oesophageal RAA segment may require the use of cardiopulmonary bypass and circulatory arrest through a median sternotomy [59]. A tight band formed by the ligamentum arteriosum may be responsible for the resultant oesophageal compression [62]. A band division may lead to immediate decompression of the oesophagus [62]. Successful robot-assisted vascular ring division has been reported for managing the patient with a RAA with the ALSA and the left-sided ligamentum arteriosum. Dividing the ligamentum adjacent to its origin from the diverticulum of the ALSA may relieve the oesophageal compression [73]. In 1 patient, a thick, taut ligamentous structure was identified, extending between the origin of the left subclavian artery and the left pulmonary artery, which was extrinsically compressing the oesophagus. The ligamentum and the diverticulum emanating from the descending aorta were dissected circumferentially, and the ligamentum was occluded with hemoclips at both ends and then divided, and tension on the diverticulum was thus immediately released [87].

\section{Cervical aortic arch}

Cervical aortic arch is a rare congenital anomaly consisting of cephalic displacement of the aortic arch (Fig. 1C). Cervical aortic arch can be classified into 5 distinct forms based on configuration of the aorta, as described by Haughton et al. [50]. Most of the patients are asymptomatic, however, a few pa- tients may become symptomatic, presenting signs of external compression including dysphagia, dyspnoea, or frequent pulmonary infections, as in 1 patient of Haughton B type cervical aortic arch with dual common carotid arteries [1]. The coarctated segment of the cervical aorta is considered the aetiology of dysphagia. What is more, the patient also presented with hypertension with severe headaches, cervical pulsatile mass and notable upper limb pressure discrepancy. Digital subtraction angiography and non-invasive imaging were preferable diagnostic tools for displaying the tortuous, elongated cervical aortic arch protruding above the clavicle, lying between distal brachiocephalic artery and proximal left subclavian artery. The surgical treatment of cervical aortic arch was to anastomose both ends of the aorta after resecting the redundant segment, usually aided by total circulatory arrest and innominate artery selective cerebral perfusion. Farsak et al. [37] reported a case of cervical aortic arch with aneurysm formation in a 24-year-old female, who presented with a pulsatile neck mass and minimal solid dysphagia. She was treated successfully with surgical resection and aorta reconstruction. However, the authors did not describe the arch branching.

\section{Kommerell's diverticulum}

Some patients with an ALSA or ARSA have an obvious dilation at the origin of the aberrant artery, which is called Kommerell's diverticulum or Kommerell's aneurysm (Fig. 1D) [26]. Kommerell's diverticulum and aberrant subclavian artery can be discovered accidentally in asymptomatic children or adults, but sometimes they are associated with complications such as compression of adjacent structures, dissections or ruptures. Dissection and rupture of an aberrant artery and Kommerell's diverticulum were reported in $20-50 \%$ of patients [61]. Kommerell's diverticulum can occur in a number of anomalies of the aortic arch system that can, sometimes, cause tracheal or oesophageal compression. It commonly occurs in cases of left aortic arch with ARSA (0.5-2.0\%) [39], or RAA with ALSA (0.05-0.1\%) [98]. In a cohort of 22 patients with ARSA, Kommerell's diverticulum was present in $37 \%$ of the cases [38]. Diverticulum at the origin of the ARSA is a remainder of the primitive right dorsal aorta. The patient with Kommerell's diverticulum may be asymptomatic, or present with dysphagia or dyspnoea [99]. ALSA with Kommerell's diverticulum may also cause dysphagia, as the aberrant right. Stan- 
dard management options of Kommerell's diverticulum are not established because of the rarity of this anomaly [61]. Surgical intervention is recommended in symptomatic patients or asymptomatic patients with large diverticulum [101]. An interposition graft or endoaneurysmorrhaphy with deep hypothermia and circulatory arrest is a traditional surgical techniques [26]. Kommerell's diverticulum may be initially misdiagnosed as RAA and partial vascular ring. Oesophagography, magnetic resonance imaging and arteriography of thoracic aorta and aortic branching can disclose saccular aneurysm of RAA, oesophageal compression and tracheal deviation [34]. Graft replacement of the diverticulum can be sufficient to relieve its symptom [94].

\section{Aberrant subclavian artery}

ARSA is the most common congenital vascular anomaly of the aortic arch, accounting for $0.5-1.8 \%$ of the cases in general population [42, 67]. Dysphagia secondary to extrinsic oesophageal compression by an ARSA is called dysphagia lusoria (Fig. 1E). In this anomaly, right subclavian artery does not arise from the brachiocephalic artery, but develops as a $4^{\text {th }}$ branch of the aortic arch that is distal to the left subclavian artery instead [84]. ARSA is located retro-oesophageally in $80-83 \%$, between the oesophagus and the trachea in $12-15 \%$ and anterior to both in $4-5 \%$ of the patients, respectively $[32,96]$. Most of the patients are asymptomatic and do not require surgical intervention, however, in a few patients, symptoms usually occur when ARSA becomes ectatic and tortuous, especially in the patients with concurrent aortic aneurysm or atherosclerosis [42]. $17 \%$ of the patients had dysphagia alone [96]. It was reported that $4(40 \%)$ patients had additional intervention for management of aneurysmal disease of the aorta or Kommerell's diverticulum, with open aortic replacement in $2(20 \%)$ and aortic endografting in $2(20 \%)$. There was $1(10 \%)$ perioperative death in a patient undergoing aortic arch debranching with placement of an aortic endograft [96]. Aberrant subclavian artery resection and reanastomosis to the ascending aorta performed via left-, or right-thoracotomy or median sternotomy under profound hypothermic circulatory arrest is a traditional surgical technique [42], and more recently, right supraclavicular cervicotomy approach is proposed
[76]. Mobilisation of the retro-oesophageal course or complete proximal resection of the lusorian artery is recommended to reduce oesophageal compression. Segmental arch replacement under partial cardiopulmonary bypass with mild to deep hypothermia, or total arch replacement under deep hypothermic cardiac arrest may be necessary [76]. Carotid subclavian bypass, carotid subclavian transposition and ascending aorta to subclavian bypass were successfully performed [96]. An endovascular stenting of a lusorian artery aneurysm for the treatment of ARSA aneurysm at Kommerell's diverticulum has obtained good results [55]. During a 2-staged surgical procedure, transpositioning of the lusoria into the right common carotid artery was performed, followed by replacement of the distal aortic arch during a second session using a single-branched Dacron tube graft [90].

\section{Pulmonary artery sling}

Pulmonary artery sling is a rare condition, in which the left pulmonary artery anomalously originates from the normally positioned right pulmonary artery (Fig. 1F). The prevalence of pulmonary artery sling is not exactly known. Respiratory symptoms are most common and are usually characterised by wheezing and stridor. A part of the patients can be associated with dysphagia. Two patients with pulmonary sling presented with severe tracheal stenosis requiring tracheal intubation [11]. A 22-year-old military man had mild dysphagia with solid foods during his military physical training activities, diagnosed with pulmonary artery sling. He had resolution of all his symptoms when he abstained from rigorous physical training exercises [69].

\section{Ligamentum arteriosum}

RAA with constricting left ligamentum arteriosum and an ARSA in vascular rings may implicate significantly in the development of tracheal or oesophageal compressions [2]. The ligaments may arise from the diverticulum and attach to the pulmonary artery and left subclavian artery. The 5-mm-thick ligamentum arteriosum connecting the left subclavian artery and the left pulmonary artery can be resected via left thoracotomy. After the operation, dysphagia immediately disappears [72]. To ensure that the external oesophageal compression is completely relieved, the aorta is pexied to the spine after the division of the ligaments [10]. 


\section{ACQUIRED CARDIOVASCULAR DYSPHAGIA}

\section{Aortic dissection/aneurysm}

Thoracic aortic aneurysm and dissection are rare causes of dysphagia [81]. Patients with dissection of ascending aorta (with intramural haematoma), aortic arch, descending aorta or an ARSA may manifest mild, intermittent [95], or progressive dysphagia [14], with occasional hoarseness [66]. Occasional dysphagia [21], mild dysphagia (right-sided aorta with Kommerell's diverticulum) [24] and weight loss can be associated symptoms to dysphagia in elderly thoracic aortic aneurysm patients [27, 29]. In non-surgical candidate or very old patients, a nasogastric tube has to be maintained [66].

Extrinsic mechanical compression of the oesophagus may result from an ectatic, tortuous, atherosclerotic, or (pseudo)aneurysmal aorta of the thoracic or thoraco-abdominal segment [27] or right-sided descending aorta [31]. Descending thoracic aortic aneurysm with an intramural thrombus may displace the oesophagus to the right [65]. Aortic pseudoaneurysm due to aortic perforation during cardiac catheterisation caused acute onset of severe dysphagia [97]. Schoder et al. [91] reported that penetrating atherosclerotic ulcers of the descending thoracic aorta caused severe dysphagia in 1 of 8 patients, and stent graft insertion resolved the symptoms. An 80-year-old female manifested a 2-month dysphagia and choking canused by a right-sided dilated atheromatous aorta [31]. a giant saccular pseudoaneurysm can also compress the distal oesophagus and the left atrium [57]. Transoesophageal echocardiography, computed tomography, magnetic resonance imaging [14], videofluoroscopic swallowing study [66], and oesophagogram [95] may reveal the nature of oesophageal compressions. Immediate aortic surgery [14] or stent graft insertion with total exclusion and shrinkage of the aneurysm may relieve the patient's symptom [82]. Expeditious endovascular stent graft exclusion of the aneurysm is indicated because of its symptomatic nature and high propensity of spontaneous rupture [57]. Thoracic aorta aneurysm resection and graft reconstruction under temporary bypass may dramatically improve the patient's symptoms [40]. A 2-stage surgical and endovascular approach including a retrograde bifurcated bypass graft from the abdominal aortic graft to the superior mesenteric and coeliac arteries and a stent-graft was once proposed [23]. An oesophageal self-expandable metal stent may be placed in very aged patients, and dysphagia can be improved rapidly [27].

\section{Left atrial enlargement}

Left atrial enlargement causes dysphagia by external compression of the oesophagus, with local high pressure zone in the oesophagus at the atrial level $[16,44]$. After the treatment for the underlying mitral regurgitation, the patient's dysphagia can be gradually alleviated [44]. Large left atrial myxoma may cause repetitive dysphagia as likely as an enlarged left atrium does [74]. Dysphagia resolves after the resection of the left atrial myxoma [74].

\section{Scoliosis}

Displaced aorta from deformatted vertebra in sclerosis causes secondary dysphagia by a mechanical obstruction of the oesophagus due to compression between the spine and the aorta [100]. The scoliosis impinges a double impression on the oesophagus [12], which may be revealed by a barium swallow or alternative imaging studies. A gastrostomy and a prophylactic fundoplication to prevent reflux may lead to a significant improvement of symptoms [12].

\section{IATROGENIC CARDIOVASCULAR DYSPHAGIA}

\section{Aorto-oesophageal fistula}

Aorto-oesophageal fistula is a rare, but fatal disorder, representing $0.01-0.08 \%$ of the cases. Common aetiologies are compressions and progressive erosions of the mid-oesophagus by aortic aneurysm, prosthetic graft or suture line, ruptured atherosclerotic ulcers in the thoracic aorta, foreign bodies, oesophageal or bronchogenic malignancies, oesophageal resections, oesophageal stenting and trauma [19]. The leading cause is the erosion of the thoracic aortic aneurysm into the oesophagus [83]. Patients with aorto-oesophageal fistula manifest a triad of mid-thoracic pain or dysphagia followed by a herald haemorrhage and fatal haematemesis. Spontaneous cessation of the herald haemorrhage may be due to temporary occlusion of the fistula due to spasm of the arterial wall, intravascular hypotension from the initial haemorrhage, and/ /or occlusion of the fistula by periaortic haematoma [6]. Replacement of the affected aorta with a tube graft is a preferred procedure. Endovascular stent graft has been proved to be of good results for aortic 
repair [5]. Embolisation of the aorto-oesophageal fistula with isobutyl-2-cyanoacrylate was considered a temporary measure for definitive surgery. However, oesophageal resection with cervical oesophagostomy is more popularly accepted.

\section{Postoperative dysphagia}

Swallowing abnormalities often develop after cardiovascular surgery in the patients with no history of previous swallowing abnormality, with $63.6 \%$ of the patients with transoesophageal echocardiography, long-term intubation or both. With hyoid, larynx and pharynx affected most commonly, signs of incomplete tilting of the epiglottis, pharyngeal weakness and postdeglutitive aspiration can be found [79]. Postoperative dysphagia was reported following vascular ring division [9], type I thoracoabdominal aneurysm repair [33], arterial switch with the Lecompte maneuver [71], coil embolisation of an aortopulmonary collateral artery [8], and thoracic endovascular aortic repair [22]. Acute dysphagic syndrome after thoracic aorta endografting has been anecdotically reported, and its aetiology remains undefined [54]. A 79-year-old woman manifested acute dysphagia after endovascular exclusion of thoracoabdominal aortic aneurysm. A barium oesophagogram demonstrated a typical 'bird's beak' appearance, with dilation of the upper and middle oesophagus. Endoscopic injections of $100 \mathrm{IU}$ of botulinum toxin a at the lower oesophageal sphincter completely relieved the symptoms [54].

\section{DISCUSSION}

Cardiovascular dysphagia can be involved in many clinical entities including ectactic, tortuous, atherosclerotic or aneurysmal aorta (dysphagia aortica), intrathoracic vascular anomalies (dysphagia lusoria), enlarged left atrium and cardiovascular manoeuvers. Upper portion of oesophagus may be impinged on directly by the thoracic aorta, and the lower portion of the oesophagus may lie between the heart and descending aorta or deformity of the distal oesophagus by a tortuous atherosclerotic aorta [75]. Dysphagia aortica is typically found in elderly women with short stature, hypertension and kyphosis [56], often with mild and indolent dysphagia [78]. Chronic thoracic aortic aneurysm may cause chronic dysphagia [85]. Treatment of dysphagia aortica depends on the severity of symptoms. Most cases are mild in nature and can be treated conservatively, whereas severe cases usually warrant surgical treatment [78].
Vascular rings and pulmonary slings are congenital anomalies of the aortic arch and pulmonary artery, which can be the underlying causes of cardiovascular dysphagia. Vascular rings could be classified into: 1) DAA; 2) RAA: a) ALSA with left ligamentum arteriosum; and b) mirror-image branching with right retro-oesophageal ligamentum arteriosum; 3) left aortic arch: a) ARSA; and b) right descending aorta and right ligamentum arteriosum; 4) anomalous innominate artery; 5) cervical aortic arch; and 6) pulmonary artery sling [64]. The incomplete vascular ring can be formed with the encircling of the trachea and oesophagus by the vascular branches [35]. The most common incomplete ring is the retro-oesophageal ARSA (arteria lusoria) with an incidence of $0.75 \%$ [48]. Located between the oesophagus and the spine, vascular abnormalities such as ARSA, right superior aortic arch and both RAA and left subclavian artery with Kommerell's diverticulum can be important, but rare causes of dysphagia in addition to respiratory distress. Complete vascular ring consisted of the RAA, Kommerell's diverticulum on the dorsal side, ascending aorta, pulmonary artery and bifurcations on the ventral side, and a ligamentum arteriosum on the left lateral side [20]. Symptoms of vascular ring including stridor, wheezing and dysphagia are due to compression of the trachea or oesophagus [35]. It is usually diagnosed in early infancy, and its presentation depends on the severity of tracheal or oesophageal compression [70]. In the elderly, dysphagia is attributable to progressively increasing size and stiffness of the vascular branches [70]. It has been reported that $25 \%$ of the patients with vascular ring presented with dysphagia, being the $6^{\text {th }}$ most common symptoms following stridor, persistent cough, chronic dyspnoea, reflux apnoea and recurrent respiratory tract infection in the patient setting [43]. Surgical management may include open and thoracoscopic approaches [92]. Infants with dysphasia of an aetiology of vascular ring compression can have their symptoms improved by video-assisted division of vascular ring [60]. In addition to chest roentgenogram, fluoroscopy, angiography in most patients, magnetic resonance imaging and computed tomography may correctly identify the vascular ring, and echocardiography can be helpful for the diagnosis [45]. Three-dimensional fast imaging with steady-state precession magnetic resonance angiography may accurately identify or exclude vascular rings or slings [46]. Endovascular aortic repair was once successful with gradually alle- 
viated symptoms and disappearance of oesophageal obstruction evidenced by follow-up barium study [15]. However, endovascular stenting may leave the periaortic haematoma or the intra-aneurysmal thrombosis in situ, which may still compress the oesophagus even after the procedure, and thus may potentially result in oesophageal ischaemia [25].

Dysphagia lusoria can develop in any age from neonate [18] to octogenarian [3]. In lusoria, blood pressure can be equal in both upper extremities [17]. A prospective study discovered that aortica lusoria coursed between Th2 and Th4 in all study cases. The mean diameter of aortica lusoria was $16.4 \pm 4.3 \mathrm{~mm}$, with an average angle of $48.8 \pm 10.7^{\circ}$, and a mean area of oesophageal compression of $194.7 \pm 90.9 \mathrm{~mm}^{2}$ [4]. The diagnostic work-up includes standard chest radiography (enlargement of aortic arch and tortuous dilated aorta), chest computed tomography (dilated thoracic aorta), endoscopy (pulsatile extrinsic compression, stenosis of the lower oesophagus with proximal dilatation), barium swallow test (partial oesophageal obstruction, pulsatile movement synchronous with aortic pulsation) and manometry (localised high pressure band with superimposed pulsation synchronous with the cardiac cycle) [7]. A barium-contrast oesophagography should be the first choice of investigation for the differential diagnosis of dysphagia in elderly patient [47]. Trimming of distal portion of the right subclavian artery with an end-to-side anastomosis to the right common carotid artery under cardiopulmonary bypass [17], total (or partial) arch replacement under deep hypothermic circulatory arrest and the arch-first technique through a bilateral submammary thoracotomy (the clamshell approach) [49] were reported for ARSA and Kommerell's diverticulum repair.

There are 2 main causes leading to aorto-oespophageal fistula: thoracic aortic aneurysm and prior thoracic aortic surgery [36]. The interval between the onset of dysphagia and bleeding from the aorto-oespophageal fistula often exceeds 1 month in the patients, thus making the aorto-oespophageal fistulas fatal. Therefore, prompt diagnosis and treatment of thoracic aortic aneurysms may increase patients' survival [28].

Cardiovascular dysphagia can be derived from a congenital, acquired or iatrogenic aetiology. The mechanisms in common are compression, tension or restraint of the oesophagus by adjacent abnormal cardiovascular structures such as aorta, arch bran- ching and left atrium. Due to the rarity of this disorder, differential diagnoses from functional or other mechanical dysphagia are mandatory, as prompt diagnosis with clear delineation of the abnormal anatomical structure and timely proper treatments might save the patients' lives in critical conditions. Treatment of cardiovascular dysphagia varies depending on aetiologies and severities of symptoms. Mild dysphagia may be conservatively managed with adjusting diet customs. Progressive and severe symptoms may warrant surgical management including relieving the girded oesophagus, oesophagomyoctomy, aortic branching dissection and re-implantation, aortic aneurysm/dissection resection and aorto-oesophageal fistula resection, etc. For patients not indicated for surgical treatment, feeding tube insertion by way of percutaneous endoscopic gastrostomy can be a good alternative. Patients with cardiovascular dysphagia usually have a good prognosis due to the benign nature of the lesion and good response to the managements.

\section{CONCLUSIONS}

Cardiovascular dysphagia is rare. The aetiologies can be congenital, acquired or iatrogenic. The severity of dysphagia can be mild or severe, consistent or progressive depending on the nature of the cardiovascular disorder and the impact for oesophageal compressions. Prompt diagnosis with clear delineation of the relevant anatomical structures is essential for further proper management. Treatment can be conservative, surgical or palliative according to the nature of the disorder and the severity of the symptom. Prognoses of the patients are always good.

\section{REFERENCES}

1. Açikel U, Uğurlu B, Hazan E, Salman E (1997) Cervical aortic arch. A case report. Angiology, 48: 659-662.

2. Adkins RB Jr, Maples MD, Graham BS, Witt TT, Davies J (1986) Dysphagia associated with an aortic arch anomaly in adults. Am Surg, 52: 238-245.

3. Akman C; Soylu N; Demir T (2005) Aberrant right subclavian artery aneurysm: report of an asymptomatic patient with a huge aneurysm. Turk Respir J, 6: 39-41.

4. Alper F, Akgun M, Kantarci M, Eroglu A, Ceyhan E, Onbas O, Duran C, Okur A (2006) Demonstration of vascular abnormalities compressing esophagus by MDCT: special focus on dysphagia lusoria. Eur J Radiol, 59: 82-87.

5. Amabile P, Collart F, Gariboldi V, Rollet G, Bartoli JM, Piquet P (2004) Surgical versus endovascular treatment of traumatic thoracic aortic rupture. J Vasc Surg, 40: 873-879.

6. Amin S, Luketich J, Wald A (1998) Aortoesophageal fistula: case report and review of the literature. Dig Dis Sci, 43: 1665-1671.

7. Antón E (2007) Dysphagia aortica: a diagnostic challenge in the elderly. Rev Esp Enferm Dig, 99: 362-364.

8. Arda IS, Guney LH, Coskun M, Hiçsönmez A (2005) Esophageal stenosis after coil embolization of an aortopulmonary collateral artery: report of a very unusual cause. J Pediatr Surg, 40: E21-E23. 
9. Backer CL, Hillman N, Mavroudis C, Holinger LD (2002) Resection of Kommerell's diverticulum and left subclavian artery transfer for recurrent symptoms after vascular ring division. Eur J Cardiothorac Surg, 22: 64-69.

10. Baird CW, Watts L (2008) Right aortic arch with multiple ligamentum arising from Kommerell's aortic diverticulum. Ann Thorac Surg, 85: 663 .

11. Bakker DA, Berger RM, Witsenburg M, Bogers AJ (1999) Vascular rings: a rare cause of common respiratory symptoms. Acta Paediatr, 88: 947-952.

12. Bar-On E, Harari M, Floman Y, Bar-Ziv J, Maayan C (1998) Compression of the esophagus by the spine and the aorta in untreated scoliosis. Arch Orthop Trauma Surg, 117: 405-407.

13. Beekman RP, Hazekamp MG, Sobotka MA, Meijboom EJ, de Roos A, Staalman CR, Beek FJ, Ottenkamp J (1998) A new diagnostic approach to vascular rings and pulmonary slings: the role of MRI. Magn Reson Imag, 16: 137-145.

14. Bekeredjian R, Steen H, Giannitsis E (2006) Aortic intramural hematoma in a 17-year-old patient with dysphagia. Clin Cardiol, 29: 373.

15. Cao DB, Gao Y, Sun XY, Yang SR (2012) Dysphagia aortica secondary to descending thoracic aortic pseudoaneurysm. Ann Thorac Surg, 94: 656.

16. Cappell MS (1995) Endoscopic, radiographic and manometric findings associated with cardiovascular dysphagia. Dig Dis Sci,40: 166-176.

17. Carrizo GJ, Marjani MA (2004) Dysphagia lusoria caused by an aberrant right subclavian artery. Tex Heart Inst J, 31: 168-171.

18. Carrozza M, Santoro G, Gaio G, Bigazzi MC, Morelli C, Caianiello G, Russo MG, Calabrò R (2007) Dysphagia lusoria due to retro-esophageal right subclavian artery in a neonate. J Cardiovasc Med (Hagerstown), 8: 547-548.

19. Carter R, Mulder GA, Snyder EN Jr, Brewer LA $3^{\text {rd }}$ (1978) Aortoesophageal fistula. Am J Surg, 136: 26-30.

20. Chen SJ, Liu KL (2007) Complete vascular ring. J Pediatr, 151: 551.

21. Cheng KC, Chiu HH, Huang CC (2009) Right aortic arch associated with Kommerell's diverticulum and aberrant left subclavian artery: an unusual cause of dysphagia. Endoscopy, 41 (suppl. 2): E157-E158.

22. Chiba D, Hanabata N, Araki Y, Sawaya M, Yoshimura T, Aoki M, Shimoyama T, Fukuda S (2013) Aortoesophageal fistula after thoracic endovascular aortic repair diagnosed and followed with endoscopy. Intern Med, 52: 451-455.

23. Chiesa R, Melissano G, Civilini E, Setacci F, Tshomba Y, Anzuini A (2004) Two-stage combined endovascular and surgical approach for recurrent thoracoabdominal aortic aneurysm. J Endovasc Ther, 11: 330-333.

24. Chiu HM, Lin JT, Chang YC, Chang YT, Tsai MC, Wang HP (2004) Right-sided aorta with Kommerell's diverticulum. Gastrointest Endosc, 60: 101-102.

25. Chocron S, Stoica L, Koch S, Bonneville JF, Kaili D, Heyd B, Etievent JP (2002) Is endovascular stent grafting for descending thoracic aortic disease recommendable in patients with dysphagia? J Thorac Cardiovasc Surg, 124: 1239-1241.

26. Cinà CS, Althani H, Pasenau J, Abouzahr L (2004) Kommerell's diverticulum and right-sided aortic arch: a cohort study and review of the literature. J Vasc Surg, 39: 131-139.

27. Coelho-Prabhu N, Baron TH (2009) Dysphagia and weight loss in an elderly person. Dysphagia aortica. Gastroenterology, 137: e1-e2.

28. Contini S, Corrente V, Nervi G, Franzè A, Scarpignato C (2006) Dysphagia aortica: a neglected symptom of aortoesophageal fistula. Dig Liver Dis, 38: 51-54.

29. Cruz RP, Marrone LC, Marrone AC (2010) Chronic syphilitic aortic aneurysm complicated with chronic aortic dissection. Am J Surg, 200: e64-e66.

30. D'Alessandro MP. Double aortic arch. Paediapaedia: Cardiovascular Diseases. http://www.virtualpediatrichospital.org/providers/ PAP/CVDiseases/DoubleAoArch.shtml.

31. De Caluwe E, Verhaegen S, Van Roey G, Janssens J, Van Gool S (2012) Dysphagia lusoria caused by a right-sided aorta. Acta Gastroenterol Belg, 75: 266-269.

32. de Jong MD, Setz-Pels W, Looij BG, Rutten MJ (2012) Aneurysm of aberrant right subclavian artery. JBR-BTR, 95: 134-135.

33. De Praetere $H$, Lerut $P$, Johan M, Daenens $K$, Houthoofd $S$, Fourneau I, Maleux G, Lerut T, Nevelsteen A (2010) Esophageal necrosis after endoprosthesis for ruptured thoracoabdominal aneurysm type I: can long-segment stent grafting of the thoracoabdominal aorta induce transmural necrosis? Ann Vasc Surg, 24: 1137.e7-e12.

34. Donatelli F, Pocar M, Pelenghi S, Moneta A, Grossi A (1997) Aortic diverticulum without vascular ring: a rare cause of dysphagia. J Vasc Surg, 26: 142-143.

35. Donato R, Lentini S, Di Bella G (2010) Magnetic resonance angiography for diagnosis of right aortic arch with vascular ring. Arch Cardiovasc Dis, 103: 631-633.

36. Eren E, Keles C, Toker ME, Ersahin S, Erentug V, Guler M, Ipek G, Akinci E, Balkanay M, Yakut C (2005) Surgical treatment of aortobronchial and aortoesophageal fistulae due to thoracic aortic aneurysm. Tex Heart Inst J, 32: 522-528.

37. Farsak B, Yilmaz M, Kaplan S, Böke E (1998) Cervical aortic arch with aneurysm formation. Eur J Cardiothorac Surg, 14: 437-439.

38. Fisher RG, Whigham CJ, Trinh C (2005) Diverticula of Kommerell and aberrant subclavian arteries complicated by aneurysms. Cardiovasc Intervent Radiol, 28: 553-560.

39. Freed K, Low VHS (1997) The aberrant subclavian artery. Am J Roentgenol, 168: 481-484.

40. Furukawa H, Tsuchiya K, Osawa H, Saito H, lida Y (1999) Saccular descending thoracic aortic aneurysm with dysphagia. Jpn J Thorac Cardiovasc Surg, 47: 277-280.

41. Gami AS, Ammash NM (2004) Images in cardiovascular medicine. Double aortic arch. Circulation, 109: 2370-2371.

42. Gardner MA, Pathare HP (2001) Aneurysms of an aberrant right subclavian artery: report of two cases. Heart Lung Circ, 10: 154-157.

43. Gormley PK, Colreavy MP, Patil N, Woods AE (1999) Congenital vascular anomalies and persistent respiratory symptoms in children. Int J Pediatr Otorhinolaryngol, 51: 23-31. Erratum in: Int J Pediatr Otorhinolaryngol, 2000; 52: 203.

44. Gotsman I, Mogle P, Shapira MY (1999) An unusual cause of dysphagia. Postgrad Med J, 75: 629-631.

45. Grathwohl KW, Afifi AY, Dillard TA, Olson JP, Heric BR (1999) Vascular rings of the thoracic aorta in adults. Am Surg, 65: 1077-1083.

46. Greil GF, Kramer U, Dammann F, Schick F, Miller S, Claussen CD, Sieverding $L$ (2005) Diagnosis of vascular rings and slings using an interleaved 3D double-slab FISP MR angiography technique. Pediatr Radiol, 35: 396-401.

47. Haliloglu N, Ozkavukcu E, Erden A (2010) Dysphagia aortica co-existing with unilateral diaphragm paralysis. Dig Liver Dis, 42: 74-75.

48. Hanazono K, Natsugoe S, Kubo M, Sakoda M, Baba M, Aikou T (2003) Esophageal cancer associated with the right aortic arch: a case study. Hepatogastroenterology, 50: 1330-1332.

49. Hata H, Shibukawa T, Satoh H (2012) Surgical repair of aberrant subclavian artery through clamshell approach. Ann Thorac Surg, 94: 1362-1364.

50. Haughton VM, Fellows KE, Rosenbaum AE (1975) The cervical aortic arches. Radiology, 114: 675-681.

51. Ireland AP. Surgical aspects of dysphagia. surgstudent.org/lectures/dys_lect.6up.pdf.

52. Jaffe RB (1991) Radiographic manifestations of congenital anomalies of the aortic arch. Radiol Clin North Am, 29: 319-334.

53. Jovancević L, Jović R, Mitrović SM (2005) Dysphagia aortica: case report. Med Pregl, 58: 401-404.

54. Kahlberg A, Marrocco-Trischitta MM, Marone EM, Amato AC, Melissano G, Chiesa R (2009) An unusual case of dysphagia after endovascular exclusion of thoracoabdominal aortic aneurysm. J Endovasc Ther, 16: 238-342.

55. Kedora J, Grimsley B, Pearl G (2009) Endovascular treatment of an aberrant right subclavian artery aneurysm with use of the Zenith iliac plug. Proc (Bayl Univ Med Cent), 22: 144-145.

56. Kim JH, Jang SW, Kim DB, Lee HJ, Kim JG, Kwon BJ, Cho EJ, Rho TH, Kim JH (2009) A patient with dysphagia due to an aortic aneurysm. Korean Circ J, 39: 258-260.

57. Kische S, Werner D, Ince H (2012) A neglected symptom of contained aortic laceration: dysphagia aortica successfully treated by endovascular stentgrafting. Catheter Cardiovasc Interv, 80: 1052-1055.

58. Kondo C, Takabayashi S, Miyake Y, Onoda K, Shimpo H, Yada I (2005) Successful surgical treatment for an adult case of double aortic arch. Jpn J Thorac Cardiovasc Surg, 53: 223-226. 
59. Konstantinov IE, Puga FJ (2001) Surgical treatment of persistent esophageal compression by an unusual form of right aortic arch. Ann Thorac Surg, 72: 2121-2123.

60. Koontz CS, Bhatia A, Forbess J, Wulkan ML (2005) Video-assisted thoracoscopic division of vascular rings in pediatric patients. Am Surg, 71: 289-291.

61. Kouchoukos NT, Masetti P (2007) Aberrant subclavian artery and Kommerell aneurysm: surgical treatment with a standard approach. J Thorac Cardiovasc Surg, 133: 888-892.

62. Koullias GJ, Korkolis DP, lams WB, Elefteriades JA (2005) Late-onset dysphagia lusoria assessed by 3-dimensional computed tomography of an aortic arch abnormality. Dis Esophagus, 18: 60-63.

63. Kubo N, Ohira M, Yamashita Y, Sakurai K, Tanaka H, Muguruma K, Kimura K, Nagahara H, Noda E, Amano R, Yashiro M, Maeda K, Hirakawa K (2012) Successful resection of esophageal carcinoma associated with double aortic arch: a case report. Anticancer Res, 32: 3351-3355.

64. Kussman BD, Geva T, McGowan FX (2004) Cardiovascular causes of airway compression. Paediatr Anaesth, 14: 60-74.

65. Lau H (2001). Dysphagia aortica: harbinger of aortoesophageal fistula? Surgery, 129: 763-764

66. Lee SI, Pyun SB, Jang DH (2006) Dysphagia and hoarseness associated with painless aortic dissection: a rare case of cardiovocal syndrome. Dysphagia, 21: 129-132.

67. Levitt B, Richter J (2007) Dysphagia lusoria: a comprehensive review. Dis Esophagus, 20: 455-460.

68. Lunde R, Sanders E, Hoskam JA (2002) Right aortic arch symptomatic in adulthood. Neth J Med, 60: 212-215.

69. Maliel K, Nasir JM, Steel K (2013) Pulmonary artery sling initially presenting with symptoms during exercise. J Am Osteopath Coll Radiol, 2: 24-26.

70. Mantini C, Santovito D, Gabrielli D, Cotroneo AR, Mezzetti A, Tartaro A, Cipollone F (2013) Extremely rare case of vascular dysphagia in an elderly man. Circulation, 127: 1049-1051.

71. McElhinney DB, Reddy VM, Reddy GP, Higgins CB, Hanley FL (1998) Esophageal compression by the aorta after arterial switch. Ann Thorac Surg, 65: 246-248.

72. Midiri M, Finazzo M, Pilato M, Lagalla R, De Maria M (1999) Right aortic arch with aberrant left innominate artery: MR imaging findings. Eur Radiol, 9: 311-315.

73. Mihaljevic T, Cannon JW, del Nido PJ (2003) Robotically assisted division of a vascular ring in children. J Thorac Cardiovasc Surg, 125: 1163-1164

74. Mishima H, Ishikawa S, Katayama Y, Matsunaga H (2014) Dysphagia caused by a left atrial myxoma. J Thorac Cardiovasc Surg, 147: $1417-1418$

75. Mittal RK, Siskind BN, Hongo M, Flye MW, McCallum RW (1986) Dysphagia aortica. Clinical, radiological, and manometric findings. Dig Dis Sci, 31: 379-384.

76. Myers PO, Fasel JH, Kalangos A, Gailloud P (2010) Arteria lusoria: developmental anatomy, clinical, radiological and surgical aspects. Ann Cardiol Angeiol, 59: 147-154

77. Ozkaya S, Sengul B, Hamsici S, Findik S (2010) An unusual cause of dyspnea. J Asthma, 47: 946-948.

78. Park SY, Lee JH, Cho SB, Lee WS, Park CH, Kim HS, Choi SK, Rew JS, Joo YE (2010) Aggravation of Dysphagia aortica after wearing the abdominal binder. J Neurogastroenterol Motil, 16: 323-326.

79. Partik BL, Scharitzer M, Schueller G, Voracek M, Schima W, Schober E, Mueller MR, Leung AN, Denk DM, Pokieser P (2003) Videofluoroscopy of swallowing abnormalities in 22 symptomatic patients after cardiovascular surgery. Am J Roentgenol, 180: 987-992.

80. Patiniotis TC, Mohajeri M, Hill DG (1995) Right aortic arch with aberrant left subclavian artery: aneurysmal dilatation causing symptomatic compression of the right main bronchus in an adult. Aust N Z J Surg, 65: 690-692.

81. Perheentupa $U$, Kinnunen I, Kujari H, Grénman R, Mäkitie AA (2010) Acute dysphagia associated with aortic dissection: a case report and review of the literature. Acta Otolaryngol, 130: 637-640.

82. Petrov I, Nedevska M, Chilingirova N, Simeonov $P$, Kratunkov $P$ Stoinova V, Nikolov D, Konteva M, Tzarianski G, Tschirkov Al (2006) Endovascular repair of dissecting thoracic aortic aneurysm in a patient with Turner syndrome. J Endovasc Ther, 13: 693-696.

83. Prokakis C, Koletsis E, Apostolakis E, Dedeilias P, Dougenis D (2008) Aortoesophageal fistulas due to thoracic aorta aneurysm: surgical versus endovascular repair. Is there a role for combined aortic management? Med Sci Monit, 14: RA48-RA54.

84. Puri S K, Ghuman S, Narang P, Sharma A, Singh S (2005) CT and MR angiography in dysphagia lusoria in adults. Indian J Radiol Imag, 15: 497-501.

85. Rábago G, Martín-Trenor A, López-Coronado JL (1999) Chronic aneurysm of the descending thoracic aorta presenting with right pleural effusion and left phrenic paralysis. Tex Heart Inst J, 26: 96-98.

86. Raymaond GS, Miller RM, Müller NL, Logan PM (1997) Congenital thoracic lesions that mimic neoplastic disease on chest radiographs of adults. Am J Roentgenol, 168: 763-769.

87. Robinson BL, Nathan M, Brown DW, Baird C, del Nido PJ (2007) Robotic division of an unusual variant of a right aortic arch. Ann Thorac Surg, 84: 670-673.

88. Salanitri J (2005) MR angiography of aberrant left subclavian artery arising from right-sided thoracic aortic arch. Br J Radiol, 78: 961-966.

89. Santoro G, Gaio G, Morelli C, Russo MG, Caianiello G, Calabrò R (2007) Dysphagia lusoria due to "abortive" double right aortic arch. Int J Cardiol, 118:e13-e15.

90. Schneider J, Baier R, Dinges C, Unger F (2007) Retroesophageal right subclavian artery (lusoria) as origin of traumatic aortic rupture. Eur J Cardiothorac Surg, 32: 385-387.

91. Schoder $M$, Grabenwöger $M$, Hölzenbein $T$, Domanovits $H$, Fleischmann D, Wolf F, Cejna M, Lammer J (2002) Endovascular stent-graft repair of complicated penetrating atherosclerotic ulcers of the descending thoracic aorta. J Vasc Surg, 36: 720-726.

92. Shah RK, Mora BN, Bacha E, Sena LM, Buonomo C, Del Nido P, Rahbar R (2007) The presentation and management of vascular rings: an otolaryngology perspective. Int J Pediatr Otorhinolaryngol, 71: 57-62.

93. Shanmugam G, Pollock J (2006) Adult dysphagia associated with type B double aortic arch. Asian Cardiovasc Thorac Ann, 14: e45-e47.

94. Shingu Y, Shiiya N, Matsuzaki K, Kunihara T, Matsui Y (2007) Dysphagia due to aortic diverticulum: an adult surgical case. Ann Thorac Cardiovasc Surg, 13: 132-134.

95. Singh S, Symons J, Ahmed A, Khosla S, Arora R (2008) Adult-onset dysphagia lusoria secondary to a dissecting aberrant right subclavian artery associated with type B acute aortic dissection. Can J Cardiol, 24: 63-65.

96. Stone WM, Ricotta JJ 2nd, Fowl RJ, Garg N, Bower TC, Money SR (2011) Contemporary management of aberrant right subclavian arteries. Ann Vasc Surg, 25: 508-514.

97. Tsao E, Cohen HL, Moore WH, Ells PF (2007) New-onset dysphagia after cardiac catheterization. Gastrointest Endosc, 66: 846-847.

98. Tsukube T, Ataka K, Sakata M, Sakata M, Wakita N, Okita Y (2001) Surgical treatment of an aneurysm in the right aortic arch with aberrant left subclavian artery. Ann Thorac Surg, 71: 1710-1711.

99. van Son JA, Konstantinov IE. Burckhard F (2002) Kommerell and Kommerell's diverticulum. Tex Heart Inst J, 29: 109-112.

100. Werner C, Rbah R, Böhm M (2006) Cardiovascular dysphagia. Clin Res Cardiol, 95: 54-56.

101. Wu JY, Chen HY, Shu CC, Yu CJ (2010) Kommerell diverticulum, right-sided aorta, and left aberrant subclavian artery in a patient with dysphagia. J Thorac Cardiovasc Surg, 139: e97-e98. 